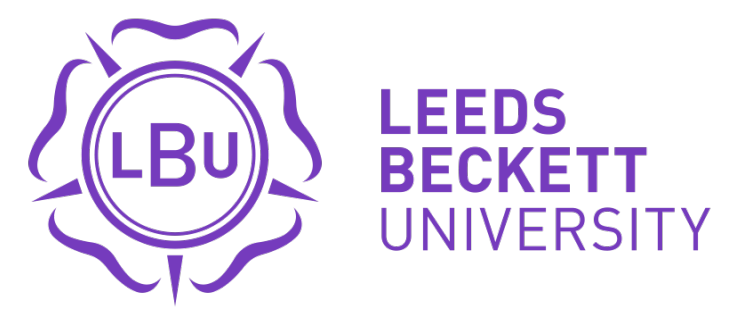

Citation:

Jones, B and Till, $\mathrm{K}$ and Emmonds, $\mathrm{S}$ and King, RFGJ and Gray, MP and Beggs, CB and O'Hara, J (2016) Hydration strategies of professional elite rugby league referees during super league matches. International Journal of Sports Science and Coaching, 11 (1). 116 - 121. ISSN 1747-9541 DOI: https://doi.org/10.1177/1747954115624811

Link to Leeds Beckett Repository record:

https://eprints.leedsbeckett.ac.uk/id/eprint/900/

Document Version:

Article (Updated Version)

The aim of the Leeds Beckett Repository is to provide open access to our research, as required by funder policies and permitted by publishers and copyright law.

The Leeds Beckett repository holds a wide range of publications, each of which has been checked for copyright and the relevant embargo period has been applied by the Research Services team.

We operate on a standard take-down policy. If you are the author or publisher of an output and you would like it removed from the repository, please contact us and we will investigate on a case-by-case basis.

Each thesis in the repository has been cleared where necessary by the author for third party copyright. If you would like a thesis to be removed from the repository or believe there is an issue with copyright, please contact us on openaccess@leedsbeckett.ac.uk and we will investigate on a case-by-case basis. 


\section{Hydration Strategies of Professional Elite Rugby League Referees during Super League Matches}

Running Title: Hydration Strategies of Rugby League Referees

Ben L. Jones ${ }^{1}$, Kevin Till ${ }^{1}$, Stacey Emmonds ${ }^{1}$, Roderick F.G.J. King ${ }^{1}$, Michael P. Gray ${ }^{1}$, Clive B. Beggs $^{2}$ and John P. O'Hara ${ }^{1}$

${ }^{1}$ Research Institute for Sport, Physical Activity and Leisure, Leeds Beckett University, Leeds, West Yorkshire, United Kingdom

${ }^{2}$ Medical Biophysics Laboratory, University of Bradford, Bradford, UK.

Dr Ben Jones - B.Jones@LeedsBeckett.ac.uk
Dr Kevin Till $-\underline{\text { K.Till@LeedsBeckett.ac.uk }}$
Stacey Emmonds $-\underline{\text { S.Emmonds@LeedsBeckett.ac.uk }}$
Prof. Roderick King - $\underline{\text { R.King@LeedsBeckett.ac.uk }}$
Michael Gray - $\underline{\text { M.Gray@LeedsBeckett.ac.uk }}$
Prof. Clive Beggs - $\underline{\text { C.B.Beggs@bradford.ac.uk }}$
Dr John O'Hara - $\underline{\text { J.OHara@LeedsBeckett.ac.uk }}$

\section{Corresponding Author:}

Dr. Benjamin Jones

Room 112, Fairfax Hall

Research Institute for Sport, Physical Activity and Leisure

Centre for Sports Performance

Headingley Campus, Leeds Beckett University

W.Yorkshire, LS6 3QS

Phone: (044-11) 01132-832600 Ext: 24009

Email: B.Jones@LeedsBeckett.ac.uk 
Hydration Strategies of Professional Elite Rugby League Referees during Super League Matches 


\begin{abstract}
Due to the focus of research within athletic populations, little is known about the hydration strategies of rugby league referees. We observed all 8 full-time professional referees, during 31 Super League matches to investigate the drinking strategies and magnitude of dehydration (body mass loss) experienced by referees during match play. Referees arrived and remained euhydrated (urine osmolality; pre and post-match $558 \pm 310$ and $466 \pm 283$ $\left.\mathrm{mOsmol} \cdot \mathrm{kg}^{-1}\right)$. Mean body mass change was $-0.7 \pm 0.8 \%$, fluid loss was $890 \pm 435 \mathrm{~g}$ and fluid intake was $444 \pm 167,438 \pm 190,254 \pm 108$ and $471 \pm 221 \mathrm{~g}$ during pre-match, first-half, halftime and second-half. This study suggests elite referees adopt appropriate hydration strategies during match-play to prevent large reductions in body mass, although individual variability was observed. Future research should investigate dehydration in referees from other sports and the effects on refereeing performance.
\end{abstract}




\section{INTRODUCTION}

Rugby league $(R L)$ is a high-intensity intermittent sport [1], officiated by referees who are employed by the Rugby Football League (RFL). The role of the referee is pivotal to RL matches, as they are required to make decisions while undertaking high intensity exercise to keep up with the game [2]. Regardless of the sport, research investigating referees is sparse in comparison to athletes. Even well-established phenomena and 'knowledge' formulated from studies based on athletic populations do not exist for referees. A specific example of this is the hydration status and strategies of elite referees during match play. As such, practitioners working with referees have little relevant evidence to apply to their practice.

Hydration or fluid balance is an area that has been widely investigated both within field [3-5] and laboratory $[6,7]$ settings for many years. The effects of hydration status on exercise performance have also been widely debated [8]. Various body mass (BM) loss thresholds have been proposed to impair both physiological and cognitive performance during exercise. A BM loss greater than $2[6,9,10]$ or $4 \%[11]$ has been suggested to negatively affect exercise performance. During RL matches, players have been reported to have an average BM loss of $1.3 \pm 0.7 \mathrm{~kg}$ (equating to $1.31 \%$ dehydration) and fluid loss of $2.0 \pm 0.7 \mathrm{~L}$ [5]. Given that referees cover more distance than players during $R L$ matches [2, 12], it is not clear if referees experience dehydration, sufficient to cause sub-optimal performance. Dehydration has also been attributed to pacing, with research showing that during team sport activity, the magnitude of dehydration is unlikely to exceed a $2 \%$ reduction in $\mathrm{BM}$, as elite players will adopt an adequate pacing strategy [13]. Given that the movement patterns of referees have been shown to be inter-related with that of players [12], it is unclear if pacing to prevent dehydration is possible. The magnitude of dehydration experienced during a match thus requires quantification. It is proposed that elite referees have habitually adopted a suitable drinking strategy during match play, which may provide a useful reference for practitioners working with sub-elite or in-experienced referees. However, to date, nothing is known about the hydration strategies of elite $R L$ referees. 
The aim of this study is to provide evidence for practitioners working with referees, by investigating the magnitude of dehydration experienced by $R L$ referees during match play or if fluid intake is sufficient to offset fluid losses. This will be achieved by determining BM change, measuring fluid intake, urine output and calculating net non-renal fluid loss in elite referees during Super League matches. This study will not only provide reference data for referees within other sports, but also ensure the safety of the employed full-time referees during their occupational activity.

\section{METHODS}

\section{Participants}

Eight professional $R L$ referees $($ age $=34 \pm 7$ years, height $=175.8 \pm 4.7 \mathrm{~cm}, \mathrm{BM}=74.4$ $\pm 14.5 \mathrm{~kg}, \dot{\mathrm{V} O}{ }_{2} \max =57.1 \pm 5.6 \mathrm{ml} \cdot \mathrm{kg}^{-1} \cdot \mathrm{min}^{-1}$, years full-time refereeing $=7 \pm 4$ years) volunteered to participate in the study. The sample is representative of all full-time $R L$ referees. All protocols received institutional ethics approval and complied with the Declaration of Helsinki on human research and international standards. Written informed consent was provided and signed, along with permission from the RFL.

\section{Design of Study}

The study was designed to investigate the arrival hydration status, pre- and post-match BM, fluid intake and urine output of elite referees during Super League match play. All procedures were designed to cause minimal disruption to referees' habitual routines. Although no pre-observation controls were employed, data collected on arrival explored the habitual arrival status of professional $R L$ referees. Likewise, data collected for the duration of match play determined habitual fluid balance, while post-match data quantified habitual fluid balance in professional $R L$ referees. A total of 31 Super League matches were observed (ranging from 1 to 
6 observations per referee). Dehydration was calculated according to the difference in pre and post-match BM and net non-renal fluid loss (referred to as fluid loss henceforth) was calculated by correcting for fluid intake and urine output between BM assessments. Fluid loss was calculated rather than sweat loss [14].

\section{Procedures}

Prior to kick-off, referees provided a urine sample into a universal container, which was analysed for osmolality (UOsmol). BM, wearing underwear, was determined to the nearest 100 g using calibrated digital scales (Seca, 700 1321008, Germany). No food was consumed post BM assessment.

Referees were provided with pre-weighed individually labelled (pre-match, first-half, halftime and second-half) drinks bottles containing water for ad libitum consumption and advised not to spit out any fluid or use for anything other than fluid intake. Video footage of matches was observed to ensure this was adhered to, which was the case for all referees. Individually labelled plastic containers (pre-match, half-time and post-match) were provided to collect urine output between pre and post-match BM assessment, allowing fluid loss calculations and assessments of UOsmol.

Post-match referees provided a urine sample into the respective plastic container to ensure an empty bladder prior to post-match BM determination, conducted in the same way as pre-match. All post-match measurements were completed prior to fluid intake after the full-time whistle.

All fluid containers were then re-weighed using bench top scales (resolution $0.001 \mathrm{~kg}$; CS-2000, Ohaus, USA). Differences in mass from pre to post-match play determined fluid intake and urine output. Only BM change, as opposed to pre and post-match BM will be presented to ensure anonymity of the referees. Ambient temperature and relative humidity $(\mathrm{RH})$ were 
measured using a digital weather station (Oregon Scientific, UK), 60 min prior to kick-off and post-match, with the mean reported.

\section{Sample Analysis}

Urine samples were analysed for osmolality using a calibrated freezing point osmometer (Genotec Osmomat 030-D, 040906, Germany). UOsmol was categorised into euhydration ( $\leq 700$ $\left.\mathrm{mOsm} \cdot \mathrm{kg}^{-1}\right)$, moderate hypohydration $\left(701-899 \mathrm{mOsm} \cdot \mathrm{kg}^{-1}\right)$ and hypohydration $(\geq 900$ $\mathrm{mOsm} \cdot \mathrm{kg}^{-1}$ ) [15]. BM change was categorised into hyperhydration (gain in BM) euhydrated (no change in $\mathrm{BM}$ ), moderately dehydrated (BM loss $0.1-3.0 \%$ ), important dehydration (BM loss $3.1-5.0 \%$ ) and severe dehydration (BM loss $>5.1 \%$ ) [16].

\section{Analysis of Data}

Data are presented as mean $\pm S D$ s. All statistical analyses were computed using SPSS version 20 (IBM, Armonk, NY, USA). A repeated measure analysis of variance (ANOVA) was used to examine the differences between time points for UOsmol (i.e., arrival, pre-match, halftime and post-match) and fluid intake (i.e., pre-match, first-half, half-time and second-half). Posthoc analysis was performed using Benjamini and Hochberg false-discovery rate analysis [17]. Pearson's correlations were performed using mean participant data points. Relationships between environmental temperature and relative humidity vs. percentage BM change, fluid loss,

fluid intake and UOsmol and relationships between UOsmol vs. fluid intake, and UOsmol between time-points were observed.

\section{RESULTS}

The ambient temperature and $\mathrm{RH}$ during match play was $19.3 \pm 2.5^{\circ} \mathrm{C}$ and $71 \pm 5.8 \%$ $\mathrm{RH}$. 
Individual mean UOsmol and output for referees is shown in table 1. There was an overall significant difference for UOsmol between time points $\left(F_{3,101}=2.44, P<0.001\right)$. Post-hoc analysis, using false-discovery rate identified no significant differences between time points. There was a significant difference for urine output between time points $\left(F_{2,73}=15.26, P<0.001\right)$. Post-hoc analysis, using false-discovery rate identified urine output was significantly greater during pre-match than at half-time $(P=0.003)$ and post-match $(P=0.033)$.

\section{${ }^{* * *}$ insert table 1 near here ${ }^{\star * *}$}

Percentage BM change, fluid intake, and fluid loss are presented in table 2. Mean BM change was $-0.7 \pm 0.8 \%$ and mean fluid loss rate was $598 \pm 371 \mathrm{~g} \cdot \mathrm{hr}^{-1}\left(7.8 \pm 4.8 \mathrm{~g} \cdot \mathrm{hr}^{-1} \cdot \mathrm{kg}^{-1}\right)$. There was a significant difference for mean fluid intake between time points $\left(F_{3,111}=7.20\right.$, $\mathrm{P}<0.001)$. Post-hoc analysis, using false-discovery rate identified fluid intake was significantly less during half-time than pre-match $(P<0.001)$, 1st half $(P=0.013)$ and 2 nd half $(P<0.001)$.

\section{${ }^{* * *}$ insert table 2 near here ${ }^{* * *}$}

When relationships were analysed between temperature, $\mathrm{RH}$ and percentage $\mathrm{BM}$ change, fluid loss, fluid intake and UOsmol, a significant relationship was only observed between temperature vs. fluid loss $(r=0.771, P=0.025)$, and temperature $v s$. first half fluid intake $(r=0.908, P=0.002)$. When relationships were analysed between UOsmol and fluid intake, UOsmol on arrival was significantly related to half-time fluid intake $(r=0.721, P=0.043)$ and pre UOsmol was significantly related to first half fluid intake $(r=0.859, P=0.006)$. When relationships were analysed between UOsmol time points, arrival UOsmol was significantly related to pre UOsmol ( $r=0.859, P=0.006)$.

\section{DISCUSSION}


The present study is the first to explore dehydration in Super League RL referees. Overall, the mean data suggests that $\mathrm{RL}$ referees arrive and remain euhydrated post-match, based on BM change and UOsmol. On $90 \%$ of observations, referees had a BM loss of $<2 \%$, thus this study provides evidence to show that hydration strategies of elite referees are mostly adequate in maintaining fluid balance during match play. On $10 \%$ of observations, referees had a BM loss $>2 \%$, although this was always less than $5 \%$ (i.e. severe dehydration; [11]). Data from this study, specifically fluid intake provides a useful reference for sub-elite referees and practitioners working with referees when devising specific hydration strategies.

BM change during exercise is a net balance of losses (fuel oxidation, respiratory water loss, urine output and sweat loss) and gains (metabolic water gain, fluid intake, food intake) [14]. During a study of this type, it is not possible to accurately quantify all BM determinants, thus BM change may not be a precise indicator of absolute changes in total body water per se. Excluding BM determinants that cannot be measured (fuel oxidation, respiratory water loss, sweat loss, metabolic water gain), the mean BM change for the $\mathrm{RL}$ referees was influenced primarily by the ratio between mean fluid intake (aggregated; pre-match, first-half, half-time, second-half) and mean fluid loss.

The mean BM loss for $R L$ referees in this study was less than those previously reported for $\mathrm{RL}$ players $(1.31 \%$ [5]). This is despite the fact referees cover more distance than players during matches $[2,12]$ which would theoretically suggest a greater degree of dehydration [10]. Contrary, RL referees lost less fluid and consumed more fluid than players during match play $(2.0 \pm 0.7$ and $0.17 \pm 0.18 L[5])$.

It is not clear whether the difference in fluid intake was due to adopted hydration strategies, thirst or the available opportunities to drink determined by match rulings, although it would be assumed that drinking opportunities would be similar for both referees and players. The differences in BM change, fluid loss and fluid intake between referees and players may be explained by the different types of activities undertaken, as players are involved in collisions / 
contact $(4.2 \pm 1.9 \%$ of total time [18]) whereas referees are not. Contrary, based on heart rate data, $R L$ referees appear to work at a similar exercise intensity to players during matches $(R L$ referees; $84.2 \pm 3.2$ [2] vs. RL players; (backs, adjustables and forwards) $83.5 \pm 1.9,81.5 \pm 4.1$, $84.1 \pm 8.2 \%$ heart rate max. [19]). Also, $\mathrm{RL}$ referees have a smaller $\mathrm{BM}$ than players $(74.4 \pm$ 14.5 vs. $96.71 \pm 8.35 \mathrm{~kg}$ [2]), which would likely reduce fluid loss [7].

It is well established that fluid (sweat) loss during exercise is influenced by environmental temperature [9], thus when developing hydration strategies, practitioners should consider the effect of the environmental conditions. This study showed a significant relationship between environmental temperature and fluid loss. Also, three referees experienced a BM loss $>2 \%$, with the greatest loss observed of $2.9 \%$, which was greater than any loss reported for Super League players during observations of a full season (2.6\% [5]). The environmental temperature and $\mathrm{RH}$ of the respected matches $\left(24,23\right.$ and $22^{\circ} \mathrm{C}$, and 70,72 and $\left.77 \% \mathrm{RH}\right)$ were greater than the study mean. It is unclear if fluid prescription greater than thirst is required, as the magnitude of dehydration was never severe in this study, although neither were environmental temperatures.

The overall trend infers $R L$ referees arrive euhydrated, similar to $R L$ players $(396 \pm 252$ $\left.\mathrm{mOsmol} \cdot \mathrm{kg}^{-1}[5]\right)$. Interestingly, when comparing $\mathrm{RL}$ referees to $\mathrm{RL}$ players, there appears to be differing prematch fluid intake habits $(0.444 \pm 0.167 \mathrm{~kg}$ vs. $0.91 \pm 0.53 \mathrm{~L}[5])$ despite both cohorts arriving euhydrated (UOsmol $\left.<700 \mathrm{mOsmol} \cdot \mathrm{kg}^{-1}[15]\right)$. It is not clear why prematch fluid intake is different (thirst or strategy) or indeed if this would have an effect on the subsequent activity. The greater prematch fluid intake in $R L$ players than referees does reconcile with the lower prematch UOsmol [5], i.e. a greater fluid intake would result in a more dilute UOsmol due to fluid turnover or paradoxical diuresis [20].

$\mathrm{BM}$ change during exercise is less in $\mathrm{RL}$ referees than soccer referees $(-1.55(0.12) \%)$, despite similarities in environmental conditions between the respective studies $\left(20.3(1.1)^{\circ} \mathrm{C}\right.$ [21]). The difference in BM change is likely a result of a lower fluid loss and greater fluid intake 
during match play in $R L$ than soccer referees $(1.60 \pm(0.13)$ and $0.32 L(0.06)$ [21]). The difference in fluid loss would be attributed to the lower total distance covered by $R L$ than football referees $(8,951 \pm 746 \mathrm{~m}$ [2] vs. $11,770 \pm 808 \mathrm{~m}$ [12]), although it is not clear if the difference in fluid intake was due to the available opportunities to consume fluid, determined by match rulings (i.e. video referee discussions in $\mathrm{RL}$ matches).

A focus for practitioners should be ensuring that all referees arrive euhydrated, as contrary to mean observations, $10 \%$ and $13 \%$ of referees arrived moderately and severely hypohydrated. An example of this was for referee 1, who was habitually severely hypohydrated (mean $919 \pm 265 \mathrm{mOsmol} \cdot \mathrm{kg}^{-1}$ ) on arrival. Although the performance of the referees was not quantified, the literature would suggest that starting exercise hypohydrated may be suboptimal [10]. Equally, the volume of fluid consumed during the pre-match period would not be adequate to replace the fluid deficit. For example, referee 1 was approximately $2 \%$ dehydrated according to UOsmol [15], thus had a fluid deficit of approximately $1.6 \mathrm{~kg}$. The pre-match fluid intake (349 $\pm 40 \mathrm{~g})$ and urine output $(180 \pm 152 \mathrm{~g})$ does not reconcile with a return to euhydrated state (based on BM change). Despite this, pre-match and half-time UOsmol $(688 \pm 40$ and $230 \pm 29$ $\mathrm{mOsmol} \cdot \mathrm{kg}^{-1}$ ) would suggest that he was euhydrated, although this would not be possible given the hydration status on arrival and further BM change $(-0.4 \pm 0.7 \%)$. Contrary to the fact arrival hydration status appears to be related to half-time fluid intake, and pre-match UOsmol was related to first half fluid intake, it is unlikely any significant fluid deficit could be restored in this limited amount of time [9]. Thus, quantifying hydration status on arrival is important, as using urine to determine hydration status when fluid is ingested, may just represent a fluid turnover and provide false-positive (dilute) in terms of establishing euhydration [10].

The differences in fluid balance identified between players and referees within a sport $(R L)$ and between sports ( $R L$ and soccer) highlight the limited generalizability of specific data from other sports, and between referees and players within a sport. Thus, due to the limited data available on referees or match officials, practitioners should not use reference data from 
players to support their hydration strategies. The findings of this study encourage future research within specific referee populations. Further research is required to investigate the correlation between hydration status and physical (work performed) and cognitive performance (decision making) within referees, in a well-controlled and real sporting setting.

In conclusion, elite $\mathrm{RL}$ referees appear to consume adequate fluid during match play to prevent large reductions in BM. Practitioners should be aware of individuals who appear to arrive hypohydrated and sport specific referee recommendations for hydration strategies should be developed. This study also recommends education sessions for individuals who habitually arrive hypohydrated. This study provides fluid intake reference data of approximately $450 \mathrm{ml}$ during prematch and each half, and $250 \mathrm{ml}$ during half time, which appears adequate to maintain fluid balance, based on mean data. Further, individual fluid intake volumes can then be prescribed based on known fluid losses or indeed an individual's thirst, but providing reference data from an elite group of referees serves as an adequate start point for sub-elite groups and practitioners.

\section{ACKNOWLEDGEMENTS}

The authors would like to acknowledge the cooperation of The Rugby Football League and all referees who participated in the study. 


\section{REFERENCES}

1. Johnston, R.D., Gabbett, T.J. and Jenkins, D.G., Applied Sport Science of Rugby League, Sports Medicine, 2014, 44, 1087-1100.

2. O'Hara, J., Brightmore, A., Till, K., Mitchell, I., Cummings, S. and Cooke, C., Evaluation of Movement and Physiological Demands of Rugby League Referees using Global Positioning Systems Tracking, International Journal of Sports Medicine, 2013, 34, 825-831.

3. Jones, B.L., O'Hara, J.P., Till, K. and King, R.F.G.J., Dehydration and Hyponatremia in Professional Rugby Union Players; A Cohort Study Observing English Premiership Rugby Union Players during Match-Play, Field and Gym Training in Cool Environmental Conditions, Journal of Strength and Conditioning Research, 2015, 29, 107-115.

4. Maughan, R.J., Merson, S.J., Broad, N.P. and Shirreffs, S.M., Fluid and Electrolyte Intake and Loss in Elite Soccer Players during Training, International Journal of Sport Nutrition and Exercise Metabolism, 2004, 14, 333-346.

5. O'Hara, J.P., Jones, B.L., Tsakirides, C., Carroll, S., Cooke, C.,B. and King, R.F.G.J., Hydration Status of Rugby League Players during Home Match-Play throughout the 2008 Super League Season, Applied Physiology, Nutrition and Metabolism, 2010, 35, 790-796.

6. Barr, S.I., Effects of Dehydration on Exercise Performance, Canadian Journal Apllied Physiology, 1999, 24, 164-172.

7. Godek, S.F., Bartolozzi, A.R. and Godek, J.J., Sweat Rate and Fluid Turnover in American Football Players Compared with Runners in a Hot and Humid Environment, British Journal of Sports Medicine, 2005, 39, 205-212.

8. Sawka, M.N. and Noakes, T.D., Does Dehydration Impair Exercise Performance, Medicine and Science in Sports and Exercise, 2007, 39, 1209-1217.

9. Baker, L.B. and Jeukendrup, A.E., Optimal Composition of Fluid-Replacement Beverages, Comprehensive Physiology, 2014, 4, 575-620.

10. Cheuvront, S.N. and Kenefick, R.W., Dehydration: Physiology, Assessment, and Performance Effects, Comprehensive Physiology, 2014, 4, 257-285.

11. Goulet, E.D.B., Effect of Exercise-Induced Dehydration on Time-Trial Exercise Performance: A Meta-Analysis, British Journal of Sports Medicine, 2011, 45, 11491156. 
12. Weston, M., Drust, B., Atkinson, G. and Gregson, W., Variability of Soccer Referees' Match Performances, International Journal of Sports Medicine, 2011, 32, 190-194.

13. Edwards, A.E. and Noackes, T.D., Dehydration: Cause of Fatigue or Sign of Pacing in Elite Soccer? Sports Medicine, 2009, 39, 1-13.

14. King, R.F.G.J., Cooke, C., Carroll, S. and O'Hara, J., Estimating Changes in Hydration Status from Changes in Body Mass: Considerations Regarding Metabolic Water and Glycogen Storage, Journal of Sports Sciences, 2008, 26, 1361-1363.

15. Shirreffs, S.M. and Maughan, R.J., Urine Osmolality and Conductivity as Indices of Hydration Status in Athletes in the Heat, Medicine and Science in Sports and Exercise, 1998, 30, 1598-1602.

16. Casa, D.J., Armstrong, L.E., Killman, S.K., Montain, S.J., Reiff, R.V., Rich, B.S.E., Roberts, W.O. and Stone, J.A., National Athletic Trainers' Association Position Statement: Fluid Replacement for Athletes, Journal of Athletic Training, 2000, 35, 212-224.

17. Strassburger, K. and Bretz, F., Compatible Simultaneous Lower Confidence Bounds for the Holm Procedure and other Bonferroni-Based Closed Tests, Statistics in Medicine, 2008, 27, 4914-4927.

18. Sykes, D., Twist, C., Hall, S., Nicholas, C. and Lamb, K., Semi-Automated TimeMotion Analysis of Senior Elite Rugby League, International Journal of Performance Analysis in Sport, 2009, 9, 47-59.

19. Waldron, M., Twist, C., Highton, J., Worsfold, P. and Daniels, M., Movement and Physiological Match Demands of Elite Rugby League using Portable Global Positioning Systems, Journal of Sports Sciences, 2011, 29, 1223-1230.

20. Noakes, T.D., Wilson, G., Gray, D.A., Lambert, M.I. and Dennis, S.C., Peak Rates of Diuresis in Healthy Humans during Oral Fluid Overload, South African Medical Journal, 2001, 91, 852-857.

21. Da Silva, A. and Fernandez, R., Dehydration of Football Referees during a Match, British Journal of Sports Medicine, 2003, 37, 502-506. 
Table 1. Urine osmolality and urine output during Super League match play in professional $R L$ referees

Urine Osmolality

\begin{tabular}{|c|c|c|c|c|c|c|c|}
\hline Referee & Arrival & $\begin{array}{l}\text { Pre- } \\
\text { Match }\end{array}$ & Half-time & $\begin{array}{l}\text { Post- } \\
\text { match }\end{array}$ & Pre-Match & Half-time & $\begin{array}{l}\text { Post- } \\
\text { match }\end{array}$ \\
\hline & \multicolumn{4}{|c|}{$\left(\mathrm{mOsmol} \cdot \mathrm{kg}^{-1}\right)$} & (g) & (g) & (g) \\
\hline 1 & $\begin{array}{c}919 \pm 265 \\
(n=4)\end{array}$ & $\begin{array}{c}688 \pm 401 \\
(n=4)\end{array}$ & $\begin{array}{c}230 \pm 29 \\
(n=2)\end{array}$ & $\begin{array}{c}722 \pm 147 \\
(n=3)\end{array}$ & $\begin{array}{c}180 \pm 152 \\
(n=4)\end{array}$ & $\begin{array}{c}163 \pm 30 \\
(n=2)\end{array}$ & $\begin{array}{c}64 \pm 33 \\
(n=3)\end{array}$ \\
\hline 2 & $\begin{array}{c}346 \pm 172 \\
(n=4)\end{array}$ & $\begin{array}{c}261 \pm 91 \\
(n=4)\end{array}$ & $\begin{array}{c}259 \pm 53 \\
(n=3)\end{array}$ & $(\mathrm{n}=0)$ & $\begin{array}{c}382 \pm 102 \\
(n=4)\end{array}$ & $\begin{array}{c}101 \pm 50 \\
(n=3)\end{array}$ & $(n=0)$ \\
\hline 3 & $\begin{array}{c}502 \pm 157 \\
(n=5)\end{array}$ & $\begin{array}{c}399 \pm 282 \\
(n=5)\end{array}$ & $\begin{array}{c}244 \pm 172 \\
(n=5)\end{array}$ & $\begin{array}{c}226 \pm 82 \\
(n=5)\end{array}$ & $\begin{array}{c}312 \pm 125 \\
(n=5)\end{array}$ & $\begin{array}{c}183 \pm 51 \\
(n=5)\end{array}$ & $\begin{array}{c}191 \pm 107 \\
(n=5)\end{array}$ \\
\hline 4 & $\begin{array}{c}760 \pm 28 \\
(n=4)\end{array}$ & $\begin{array}{c}688 \pm 90 \\
(n=4)\end{array}$ & $\begin{array}{c}661 \pm 51 \\
(n=4)\end{array}$ & $\begin{array}{c}749 \pm 57 \\
(n=2)\end{array}$ & $\begin{array}{c}209 \pm 83 \\
(n=4)\end{array}$ & $\begin{array}{c}86 \pm 42 \\
(n=4)\end{array}$ & $\begin{array}{c}90 \pm 82 \\
(n=2)\end{array}$ \\
\hline 5 & $\begin{array}{c}457 \pm 28 \\
(n=6)\end{array}$ & $\begin{array}{c}531 \pm 430 \\
(n=6)\end{array}$ & $\begin{array}{c}416 \pm 339 \\
(n=5)\end{array}$ & $\begin{array}{c}487 \pm 353 \\
(n=5)\end{array}$ & $\begin{array}{c}183 \pm 68 \\
(n=6)\end{array}$ & $\begin{array}{c}85 \pm 42 \\
(n=5)\end{array}$ & $\begin{array}{c}119 \pm 42 \\
(n=5)\end{array}$ \\
\hline 6 & $\begin{array}{c}771 \pm 76 \\
(n=2)\end{array}$ & $\begin{array}{c}556 \pm 41 \\
(n=2)\end{array}$ & $\begin{array}{c}245 \pm 85 \\
(n=2)\end{array}$ & $\begin{array}{c}202 \pm 93 \\
(n=2)\end{array}$ & $\begin{array}{c}155 \pm 81 \\
(n=2)\end{array}$ & $\begin{array}{c}173 \pm 194 \\
(n=2)\end{array}$ & $\begin{array}{c}269 \pm 214 \\
(n=2)\end{array}$ \\
\hline 7 & $\begin{array}{c}432 \pm 438 \\
(\mathrm{n}=5)\end{array}$ & $\begin{array}{c}194 \pm 133 \\
(n=5)\end{array}$ & $\begin{array}{c}286 \pm 30 \\
(n=4)\end{array}$ & $\begin{array}{c}496 \\
(n=1)\end{array}$ & $\begin{array}{c}396 \pm 199 \\
(n=5)\end{array}$ & $\begin{array}{c}94 \pm 43 \\
(n=4)\end{array}$ & $\begin{array}{c}106 \\
(n=1)\end{array}$ \\
\hline 8 & $\begin{array}{c}136 \\
(n=1)\end{array}$ & $\begin{array}{c}161 \\
(n=1)\end{array}$ & $\begin{array}{c}365 \\
(n=1)\end{array}$ & $\begin{array}{c}734 \\
(n=1)\end{array}$ & $\begin{array}{c}554 \\
(n=1)\end{array}$ & $\begin{array}{c}154 \\
(n=1)\end{array}$ & $\begin{array}{c}116 \\
(n=1)\end{array}$ \\
\hline $\begin{array}{c}\text { Mean } \pm \\
\text { SD }\end{array}$ & $\begin{array}{c}558 \pm \\
310 \\
(n=31)\end{array}$ & $\begin{array}{c}448 \\
\pm 307 \\
(\mathrm{n}=31)\end{array}$ & $\begin{array}{c}353 \pm \\
216 \\
(n=26)\end{array}$ & $\begin{array}{c}466 \pm \\
283 \\
(n=19)\end{array}$ & $\begin{array}{c}280 \pm \\
155^{\mathrm{a}} \\
(\mathrm{n}=31)\end{array}$ & $\begin{array}{c}121 \pm \\
68 \\
(n=26)\end{array}$ & $\begin{array}{c}114 \pm \\
100 \\
(n=19)\end{array}$ \\
\hline
\end{tabular}

a significantly different to half-time $(P=0.003)$ and post-match $(P=0.033)$. 
1 Table 2. Percentage BM change, fluid loss and fluid intake during Super League match play in professional RL referees

2

\begin{tabular}{|c|c|c|c|c|c|c|}
\hline Referee & $\begin{array}{l}\text { Percentage BM } \\
\text { Change }\end{array}$ & $\begin{array}{c}\text { Calculated Fluid } \\
\text { Loss }\end{array}$ & $\begin{array}{c}\text { Prematch Fluid } \\
\text { Intake }\end{array}$ & $\begin{array}{l}\text { First-half } \\
\text { Fluid Intake }\end{array}$ & $\begin{array}{l}\text { Half-time } \\
\text { Fluid Intake }\end{array}$ & $\begin{array}{l}\text { Second-half } \\
\text { Fluid Intake }\end{array}$ \\
\hline & $(\%)$ & (g) & (g) & (g) & (g) & (g) \\
\hline $1(n=4)$ & $-0.4 \pm 0.7$ & $924 \pm 351$ & $349 \pm 40$ & $491 \pm 158$ & $214 \pm 29$ & $394 \pm 154$ \\
\hline $2(n=4)$ & $-0.6 \pm 1.0$ & $871 \pm 460$ & $325 \pm 124$ & $503 \pm 158$ & $319 \pm 75$ & $502 \pm 258$ \\
\hline $3(n=5)$ & $-0.6 \pm 0.6$ & $651 \pm 128$ & $374 \pm 65$ & $442 \pm 212$ & $184 \pm 55$ & $521 \pm 163$ \\
\hline $4(n=4)$ & $-1.0 \pm 0.5$ & $1094 \pm 537$ & $408 \pm 160$ & $567 \pm 248$ & $0 \pm 0$ & $458 \pm 321$ \\
\hline $5(n=6)$ & $-1.0 \pm 1.0$ & $950 \pm 543$ & $445 \pm 76$ & $392 \pm 167$ & $223 \pm 54$ & $449 \pm 264$ \\
\hline $6(n=2)$ & $-0.9 \pm 0.4$ & $907 \pm 869$ & $765 \pm 256$ & $401 \pm 38$ & $193 \pm 38$ & $337 \pm 162$ \\
\hline $7(n=5)$ & $-0.5 \pm 1.0$ & $1036 \pm 272$ & $559 \pm 216$ & $393 \pm 169$ & $540 \pm 23$ & $576 \pm 251$ \\
\hline $8(n=1)$ & -0.7 & 88 & 576 & 0 & 494 & 336 \\
\hline Mean $\pm \operatorname{SD}(n=31)$ & $-0.7 \pm 0.8$ & $890 \pm 435$ & $444 \pm 167$ & $438 \pm 190$ & $254 \pm 108^{a}$ & $471 \pm 221$ \\
\hline
\end{tabular}

3

${ }^{a}$ significantly different to pre-match $(P<0.001)$, first-half $(P=0.013)$ and second-half $(P<0.001)$. 